\title{
Use of a CAD-CAM inferior alveolar nerve salvage template during mandibular resection for benign lesions
}

\section{Utilizzo di una guida CAD-CAM per la preservazione del nervo alveolare inferiore durante le resezioni mandibolari nelle lesioni benigne}

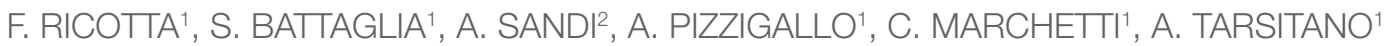 \\ ${ }^{1}$ Maxillofacial Surgery Unit, Head and Neck Department, S. Orsola-Malpighi Hospital, Department of Biomedical \\ and Neuromotor Sciences, Alma Mater Studiorum University of Bologna, Bologna, Italy; ${ }^{2}$ Sintac Biomedical \\ Engineering, Trento, Italy
}

\section{SUMMARY}

During surgical procedures involving the mandible, preserving the inferior alveolar nerve (IAN) may be preferable for benign tumours. In this prospective pilot study, we report our experience on the use of a Rapid Inferior Alveolar nerve Customised Salvage (RICS) template. Virtual surgical planning (VSP) of the template is based on a 3D model obtained from the elaboration of DICOM files of the preoperative CT scan. Five patients affected by benign mandibular pathology were included. A total of 7 IANs were exteriorised. The average time of exteriorisation was 23 minutes. All exteriorisations were performed successfully and no damage to the neuro-vascular bundle occurred. All patients showed complete recovery of sensitivity of the IAN within 7 weeks after surgical procedure. In conclusion, RICS template seems to allow faster and safer exteriorisation of the IAN.

KEY WORDS: Mandibular resection • Inferior alveolar nerve • Nerve exteriorisation • Computer-assisted surgery

\section{RIASSUNTO}

Durante le procedure chirurgiche di resezione mandibolare, la preservazione del nervo alveolare inferiore (NAI) è auspicabile nella patologia benigna. In questo studio pilota prospettico, riportiamo la nostra esperienza nell'uso di una dima di taglio customizzata per la rapida preservazione del nervo alveolare inferiore (RICS). La pianificazione chirurgica virtuale della guida di taglio è basata sul modello $3 D$ ottenuto dall'elaborazione dei file DICOM della TC pre-operatoria. Sono stati inclusi nel nostro studio 5 pazienti affetti da patologia mandibolare benigna. Sono stati esteriorizzati in totale 7 NAI. Il tempo medio di esteriorizzazione è stato 23 minuti. Tutte le esteriorizzazioni sono state eseguite con successo e non è avvenuto alcun danneggiamento del fascio neuro-vascolare. Tutti i pazienti hanno mostrato il recupero completo della sensibilità del NAI entro 7 settimane dall'intervento chirurgico. In conclusione, la dima di esteriorizzazione RICS sembrerebbe permettere una più rapida e sicura preservazione del NAI.

PAROLE CHIAVE: Resezione mandibolare $\bullet$ Nervo alveolare inferiore $\bullet$ Esteriorizzazione del nervo $\bullet$ Chirurgia computer-assistita

\section{Introduction}

Inferior alveolar nerve (IAN) damage occurs often in patients with mandibular traumas, neoplasms, or iatrogenic injuries ${ }^{12}$; it is followed by hypoaesthesia, paraesthesia and hyperaesthesia in the area innervated by the nerve (the inferior lip and chin) ${ }^{3}$.

In particular, in locally-advanced or relapsed lesions involving the mandible, although the nerve is not directly involved by the disease, it is often sacrificed when segmental mandibular resection is performed.

In order to preserve the IAN, nerve exteriorisation can be executed. The surgical steps are as follows:
- exposure of the mental nerve;

- starting from the mental foramen, a saw or rotating burr is used to perform osteoplasty of the outer cortex of the lower jaw, proceeding as distal as necessary from the mental foramen;

- Exteriorisation of the IAN using a blunt instrument (a free periosteal elevator).

These steps require great care as the surgeon can damage the nerve during exteriorisation ${ }^{1}$.

Performing the surgical procedure as previously described, there is a considerable risk of iatrogenic nerve injury ${ }^{4}$. With the advent of computer-assisted surgery 
(CAS), virtual surgical planning and CAD/CAM-fabrication of exteriorisation templated becomes possible.

The aim of this pilot study was to investigate if the use of $\mathrm{CAD} / \mathrm{CAM}$-fabricated exteriorisation templates is feasible and can contribute to reduce operation time and the incidence of nerve damage.

\section{Materials and methods}

The present study is a prospective single-centre pilot study. The study was approved by the S. Orsola Hospital Ethics Committee (approval no. 57/2011/O/Disp). Between November 2016 and January 2018, 5 patients affected by locally advanced or relapsed benign diseases, for a total of 7 IAN exteriorisations, were included. The inclusion criteria were:

- benign locally advanced lesion involving the mandible with need for segmental resection. (the indications to perform mandibular segmental resection are reported for each case in Table I);

- preoperative CT scan imaging;

- clinical and radiological signs of IAN integrity;

- absence of extra-mandibular vestibular extension.

Exclusion criteria were:

- malignancies of the mandible;

- clinical and radiological signs of IAN involvement;

- extra-mandibular vestibular extension.

All surgical and reconstructive procedures were virtually planned and performed according to our CAD-CAM protocol $^{5}$.

Virtual planning began with the acquisition of a high-resolution CT-scan of the craniofacial region and of the lower leg or ankle as a donor site. Digital Imaging and Communications in Medicine (DICOM) format data were processed using the simulation software. Using this software, it is possible to create 3D virtual models of the maxillofacial skeleton and donor site. The software allows the surgeon to plan mandibular and flap osteotomies.

Mandibular cutting guides were used to reproduce the osteotomy site, as virtually planned. Reconstructive plates were manufactured by a direct metal laser sintering method: a metal powder was fused into a solid component and melted locally using a focused laser beam. The solid-to-layer files of the guide and plate were then manufactured by direct metal laser sintering (SINTAC s.r.l., Biomedical Engineering, Trento, Italy) using an EOSINT M270 system (Electro-Optical Systems, GmbH, Munich, Germany).

Protocol for RICS computer-assisted design and manufacturing

DICOM files were processed using MIMICS software (Materialise, Leuven, Belgium) to obtain 3D virtual models, and the surgeons then engaged in virtual surgical planning (VSP). Cutting guides and Rapid Inferior alveolar nerve Customised Salvage (RICS) templates were designed using 3MATIC software (Materialise). The RICS template featured appropriate threshold of the IAN path in the mandibular canal (Fig. 1). The exteriorisation guide was planned based on the projection of the nerve on the outer surface of the mandible. All templates featured at least two stabilisation flanges. The virtual planning files were verified using MAGICS software (Materialise). The STL files of the cutting guides and the RICS template were additively printed

Table I. Characteristics of patients enrolled and pathologies for the test group; Indications to segmental mandibular resection; Time of sensory recovery and time of nerve exteriorisation using the RICS template.

\begin{tabular}{|c|c|c|c|c|c|c|c|c|}
\hline $\begin{array}{l}\text { Patient } \\
\text { (sex) }\end{array}$ & Pathology & $\begin{array}{l}\text { Indication to segmental } \\
\text { resection }\end{array}$ & Side & Defect type & Free flap & Age & $\begin{array}{c}\text { Time } \\
\text { (minutes) }\end{array}$ & $\begin{array}{c}\text { Sensory } \\
\text { recovery } \\
\text { time } \\
\text { (weeks) }\end{array}$ \\
\hline I (F) & Ameloblastoma & $\begin{array}{l}\text { Second local relapselextra- } \\
\text { cortical lingual extension }\end{array}$ & Right & Body & \|liac crest & 31 & 25 & 7 \\
\hline \| (M) & $\begin{array}{l}\text { Desmoplastic } \\
\text { Fibroma }\end{array}$ & $\begin{array}{l}\text { Extra-cortical lingual } \\
\text { extension }\end{array}$ & Left & Body & Fibula & 9 & 19 & 5 \\
\hline III (F) & Osteomyelitis & $\begin{array}{c}\text { Relapse after conservative } \\
\text { surgery }\end{array}$ & Right; Left & $\begin{array}{l}\text { Ramus, } \\
\text { Body, } \\
\text { Symphysis, } \\
\text { Body }\end{array}$ & Fibula & 25 & $26 ; 20$ & $4+6$ \\
\hline IV (M) & BRONJ & $\begin{array}{c}\text { Stage III according to AAOMS } \\
\text { classification }\end{array}$ & Right; Left & $\begin{array}{l}\text { Body, } \\
\text { Symphysis, } \\
\text { Body }\end{array}$ & Fibula & 55 & $30 ; 22$ & $5+7$ \\
\hline$V(F)$ & Osteomyelitis & $\begin{array}{l}\text { Second relapse after } \\
\text { conservative surgery }\end{array}$ & Left & Body & Fibula & 24 & 20 & 1 \\
\hline
\end{tabular}




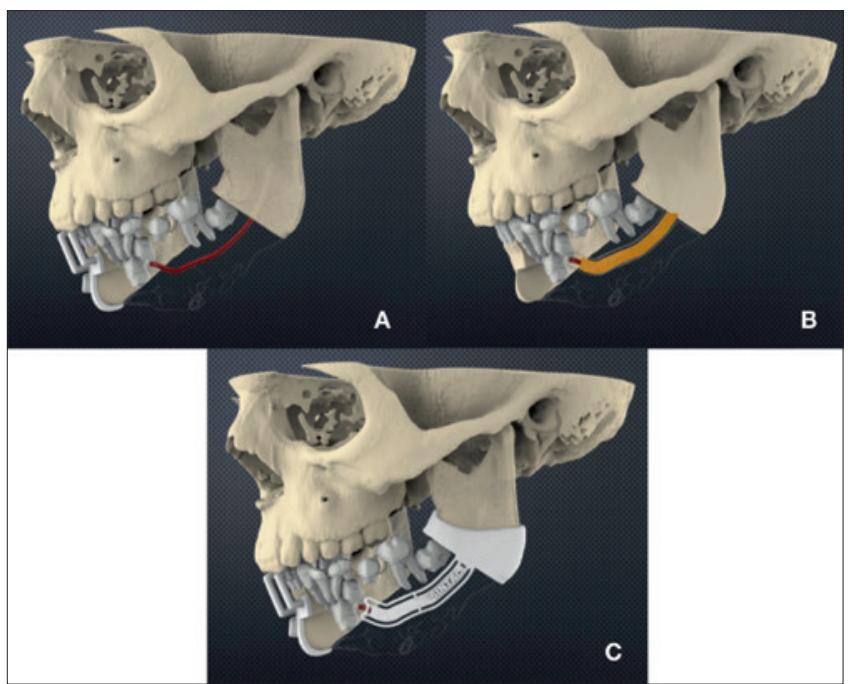

Fig. 1. Virtual planning of the RICS template for exteriorisation of the IAN. A: Appropriate thresholding to visualise the path of the IAN. B: Outlining of the IAN on the outer cortex of the mandibular canal. C: Design of the RICS template.

using the SLS FORMIGA P110 system (Electro-Optical Systems GmbH, Krailling, Germany) by SINTAC s.r.l., Biomedical Engineering (Trento, Italy).

\section{Surgical procedure}

The procedure featured the creation of a surgical access and the exposure of the mandible to an extent permitting template positioning. The mental foramen and its nerve were identified, and the RICS template was positioned (Fig. 2). Osteoplasty of the outer mandibular cortex then continued, following the guide to attain the bone marrow. Commence-

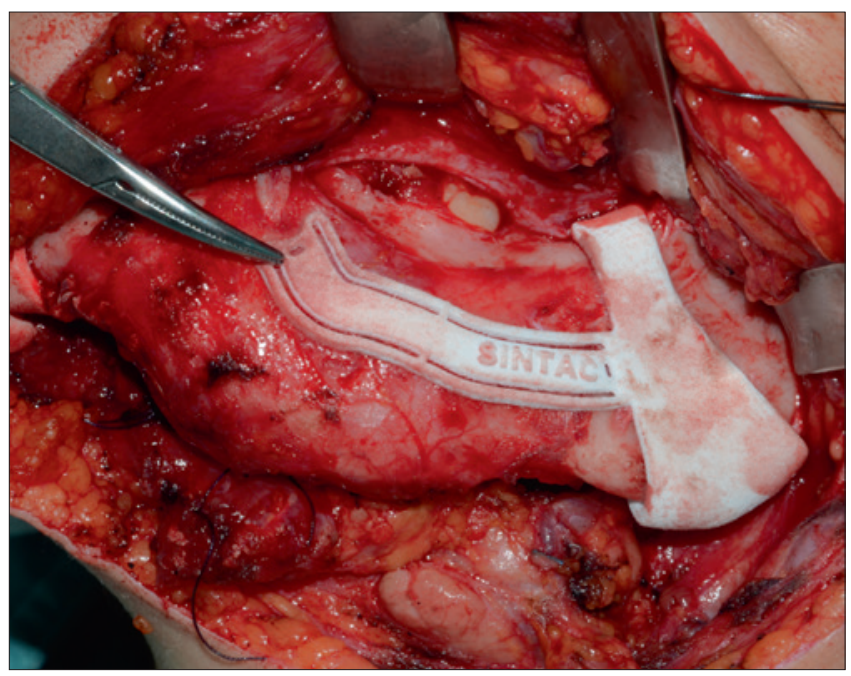

Fig. 2. Intra-operative positioning of the RICS template.

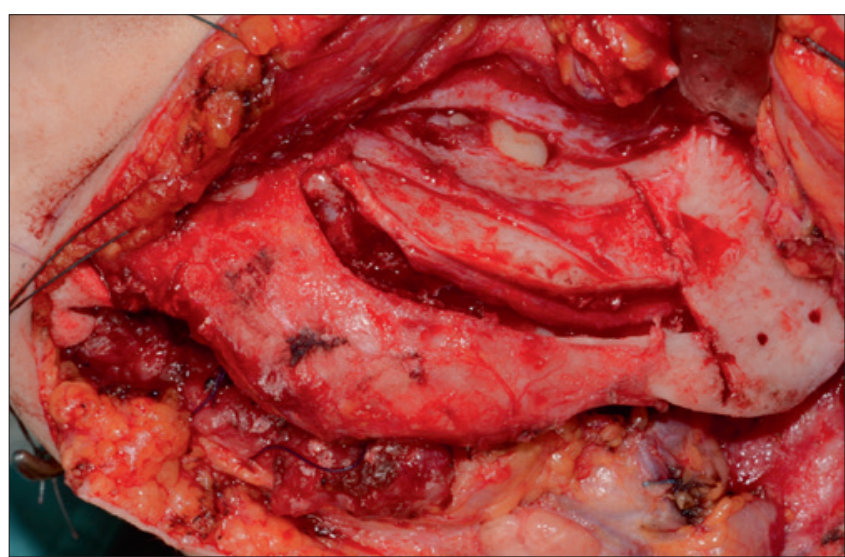

Fig. 3. The outer cortex of the mandible is removed. Complete visualisation and exteriorisation of the IAN.

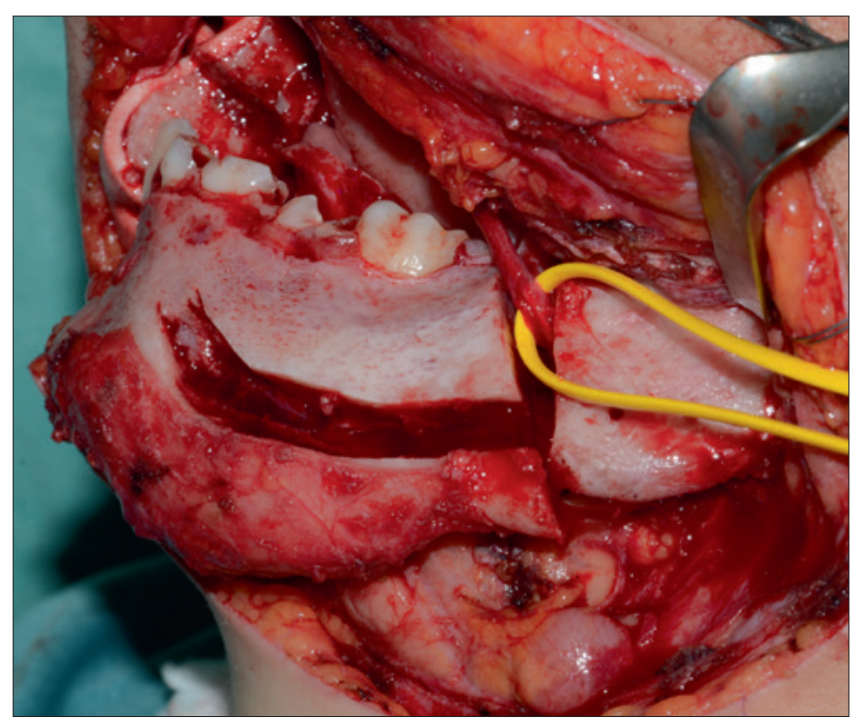

Fig. 4. The mandibular resection is performed with preservation of the IAN (yellow loop), as preoperatively planned.

ment of bleeding indicated that the depth at which osteotomy of the outer cortex should proceed, with exposure of the nerve canal, had been attained. Osteoplasty was usually performed with the aid of a piezoelectric saw (Piezosurgery, Mectron Spa, Carasco, Italy). When the osteotomy lines were traced, it was possible to finalise the procedure after template removal, which created more space for the saw. After osteoplasty was complete, we removed the outlined mandibular cortex and exposed the IAN along its entire path (Fig. 3). The IAN was completely removed from its canal via blunt dissection, taking care not to pull, compress, or strain the nerve to avoid ischaemic/iatrogenic damage. When exteriorisation was complete, safe mandibular resection proceeded as planned (Fig. 4). 


\section{Outcome evaluation}

The exteriorisation time was recorded for each nerve, intended as from the positioning of the RICS template to the completion of the IAN exteriorisation from its canal. Feasibility of the procedure was evaluated as the correspondence between VSP-related positioning of the RICS template and its real intra-operative reproducibility.

Success of the surgical procedure was considered as nerve bundle preservation.

The sensitivity status of each enrolled patient was clinically assessed.

The "two point discrimination test" ${ }^{67}$ was performed after surgical procedure, as follows:

- Post-op - Day \#1

- Post-op - Week \#1

- Post-op - Week \#3

- Post-op - Week \#5

- Post-op - Week \#7

Results obtained were registered on the patient's medical records.

A historical control group constituted of 5 patients (six IANs), treated without template, was considered to compare clinical outcomes.

\section{Results}

Seven IANs were exteriorised (two patients required bilateral exteriorisation) for the test group. The procedures were performed by three surgeons differing in age and experience.

All treated patients, but one, presented trophic alveolar bone (Cawood and Howell class I-II) ${ }^{8}$ and were potentially eligible for implant-supported dental rehabilitation. One patient had class IV according to Cawood and Howell classification ${ }^{8}$.

All patients underwent bony free flap reconstruction. Four patients had a fibula free flap; One patient had an iliac crest free flap (Table I).

In all cases treated, we found good correspondence between VSP and intra-operative positioning of the RICS template. Osteoplasty was successfully performed according to the template, allowing us to expose the IAN. All exteriorisations were successful, and the neuro-vascular bundle was not damaged.

The average exteriorisation time was 23 min (range 19-30 min) for the test group and 38 (range 29-48 min) min for the control group. In the immediate post-operative period, all patients exhibited hypoaesthesia, paraesthesia, or anaesthesia of the territory innervated by the IAN, as assessed using "two-point discrimination".

All patients treated using the RICS template exhibited complete recovery of IAN sensitivity within 7 weeks of surgery. The average recovery time was 5 weeks (range 1-7 weeks). Otherwise, the average recovery time was 8 weeks (range 6-10 weeks) for the control group.

The mean cost registered for each RICS template was 400 euro.

\section{Discussion}

The IAN exteriorisation an established procedure for the salvage of the mandibular neuro-vascular bundle.

Many reports have confirmed the utility of the procedure, especially during dental rehabilitation. Two exteriorisation techniques have been described: inferior alveolar nerve transposition (IANT) ${ }^{9}$ and inferior alveolar nerve lateralisation (LIAN) ${ }^{10}$.

In our experience, IAN exteriorisation is valuable, especially in those with benign pathologies that do not involve the mandibular canal. In such cases, when segmental mandibular resection is indicated for relapsed lesions or locally advanced disease, nerve salvage is possible, albeit associated with a longer operative time, allowing recovery of IAN sensitivity.

Traditional exteriorisation proceeds after evaluation of diagnostic images, either 2D OPG or 3D CT. The surgeon checks the position of the nerve and then performs outer cortical osteotomy. This places the nerve at risk. Therefore, a piezoelectric saw, which reduces the risk of bundle lesion, is generally employed at this stage ${ }^{11} 12$. However, during mandibular resection, the risk is particularly high because a full-thickness bone osteotomy is required.

In this pilot study, we propose a customised template to evaluate the feasibility of this kind of tool.

The use of patient-specific cutting guides during mandibular resection to treat benign pathologies and malignancies improves outcomes and reconstruction accuracy ${ }^{13} 14$. Huang described a mandibular cutting guide used to salvage the IAN in six patients with benign pathologies ${ }^{15}$. The guide was planned by reference to the inferior border of the mandibular canal; an osteotomy line was placed only on that border. Moreover, only one large cutting guide was used for both resection and nerve exteriorisation. Our RICS template is a dedicated exteriorisation guide and is thus distinct from the resection cutting guide. The RICS template is small and can be positioned via a minimal surgical access. Moreover, the template is a two-track guide outlining both the superior and inferior borders of the mandibular canal, allowing more precise osteotomy. Nerve exteriorisation is rapid, precise and delicate. All cases exhibited rapid recovery of sensitivity.

The mean cost for each RICS template was 400 euro. We 
consider this cost adequate in relation to sparing of surgical time and improvement in terms of clinical outcomes. Finally, our pilot study showed that use of the RICS template provided adequate reproducibility. Although three surgeons differing in age and experience performed the procedure, the results (exteriorisation time and time to recovery of sensitivity) were similar.

\section{Conclusions}

In conclusion, we believe that the RICS template allows faster and safer exteriorisation of the IAN. Moreover, the use of a template renders the procedure reproducible and the time to recovery of sensation short. These preliminary results suggest that, although more studies and larger case series are needed to properly evaluate the feasibility of the technique, our template seems to be a good starting point for the fabrication of such devices.

\section{Conflict of interest statement}

None declared.

\section{References}

1 Mozsary PG, Syers CS. Microsurgical correction of the injured inferior alveolar nerve. J Oral Maxillofac Surg 1985;43:353-8.

2 Upton LG, Rajvanakarn M, Hayward JR. Evaluation of the regenerative capacity of the inferior alveolar nerve following surgical trauma. J Oral Maxillofac Surg 1987;45:212-6.

3 Sandstedt P, Sorensen S. Neurosensory disturbances of the trigeminal nerve: a long-term follow-up of traumatic injuries. J Oral Maxillofac Surg 1995;53:498-505.
4 Nocini PF, De Santis D, Fracasso E, et al. Clinical and electrophysiological assessment of inferior alveolar nerve function after lateral nerve transposition. Clin Oral Implants Res 1999;10:120-30.

5 Tarsitano A, Del Corso G, Ciocca L, et al. Mandibular reconstructions using computer-aided design/computer-aided manufacturing: A systematic review of a defect-based reconstructive algorithm. $\mathrm{J}$ Craniomaxillofac Surg 2015;43:1785-91.

6 Hirsch JM and Branemark PI. Fixture stability and nerve function after transposition and lateralization of the inferior alveolar nerve and fixture installation. Br J Oral Maxillofac Surg 1995;33:276-81.

7 Khajehahmadi S, Rahpeyma A, Bidar M, et al. Vitality of intact teeth anterior to the mental foramen after inferior alveolar nerve repositioning: nerve transpositioning versus nerve lateralization. Int $\mathbf{J}$ Oral Maxillofac Surg 2013;42:107-8.

8 Cawood JI, Howell RA. A classification of the edentulous jaws. Int J Oral Maxillofac Surg 1988;17:232-6.

9 Peleg M, Mazor Z, Chaushu G, et al. Lateralization of the inferior alveolar nerve with simultaneous implant placement: a modified technique. Int J Oral Maxillofac Implants 2002;17:101-6.

10 Friberg B, Ivanoff CJ, Lekholm U. Inferior alveolar nerve transposition in combination with Brånemark implant treatment. Int J Periodontics Restorative Dent 1992;12:440-9.

11 Proussaefs P. Vertical alveolar ridge augmentation prior to inferior alveolar nerve repositioning: a patient report. Int J Oral Maxillofac Implants 2005;20:296-301.

12 Bovi M, Manni A, Mavriqi L, et al. The use of piezosurgery to mobilize the mandibular alveolar nerve followed immediately by implant insertion: a case series evaluating neurosensory disturbance. Int $\mathrm{J}$ Periodontics Restorative Dent 2010;30:73-81.

13 Tarsitano A, Mazzoni S, Cipriani R, et al. The CAD-CAM technique for mandibular reconstruction: an 18 patients oncological case-series. J Craniomaxillofac Surg 2014;42:1460-4.

14 Tarsitano A, Ciocca L, Cipriani R. Mandibular reconstruction using fibula free flap harvested using a customised cutting guide: how we do it. Acta Otorhinolaryngol Ital 2015;35:198-201.

15 Huang D, Chen M, He D, et al. Preservation of the inferior alveolar neurovascular bundle in the osteotomy of benign lesions of the mandible using a digital template. Br J Oral Maxillofac Surg 2015;53:637-41.

Received: November 5, 2018 - Accepted: November 27, 2018

How to cite this article: Ricotta F, Battaglia S, Sandi A, et al. Use of a CAD-CAM inferior alveolar nerve salvage template during mandibular resection for benign lesions. Acta Otorhinolaryngol Ital 2019;39:117-121. https://doi.org/10.14639/0392-100X-2408

Address for correspondence: Achille Tarsitano, Maxillofacial Surgery Unit, S. Orsola-Malpighi Hospital, Department of Biomedical and Neuromotor Sciences, Alma Mater Studiorum University of Bologna, via G. Massarenti 9, 40100 Bologna, Italy. Tel. +39 0512144205. E-mail: achille.tarsitano2@unibo.it 